\title{
Carboxymethylated tetrahydropyridoindoles as aldose reductase inhibitors: in vitro selectivity study in intact rat erythrocytes in relation to glycolytic pathway
}

\author{
Maria Juskova, Vladimir Snirc, Alena Gajdosikova, Andrej Gajdosik, Ludmila Krizanova \\ and Milan Stefek
}

Institute of Experimental Pharmacology, Slovak Academy of Sciences, Dúbravská cesta 9, 84104 Bratislava, Slovakia; E-mail: exfastfk@savba.sk

\begin{abstract}
Oxidative stress and polyol pathway hypotheses are generally accepted in the etiology of diabetic complications. Recently, novel carboxymethylated pyridoindoles, structural analogues of the efficient chain-breaking antioxidant stobadine, were designed, synthesised and characterised as prospective aldose reductase inhibitors endowed with antioxidant activity. Of them (2-benzyl2,3,4,5-tetrahydro-1H-pyrido[4,3-b]indole-8-yl)-acetic acid (compound 1) and (2-phenethyl2,3,4,5-tetrahydro-1H-pyrido[4,3-b]indole-8-yl)-acetic acid (compound 2) were found to be the most efficient inhibitors of aldose reductase with the corresponding $\mathrm{IC}_{50}$ values in a micromolar region. The aim of this work was to study cellular uptake of the novel pyridoindole derivatives and their effect on the complex metabolism of glucose in isolated rat erythrocytes under euglycaemic conditions. Glycolysis was shown to be the sole process responsible for the observed clearance of glucose. The compounds studied were avidly taken up by the cells, yet they did not significantly affect glucose consumption and lactate production nor did they affect osmotic fragility of the erythrocytes. On balance, the present experimental findings indicate that compounds 1 and 2, efficient inhibitors of aldose reductase, are selective in relation to the glycolytic pathway of glucose elimination. This conclusion supports current preclinical development of novel carboxymethylated tetrahydropyridoindoles as promising aldose reductase inhibitors for pharmacological prevention and treatment of diabetic complications.
\end{abstract}

Key words: Tetrahydropyridoindoles - Aldose reductase inhibitors - Glycolysis - Polyol pathway - Rat erythrocytes

\section{Introduction}

The primary physiological function of the red blood cell (RBC) is to transport oxygen. In addition, there are several metabolic functions that a RBC must perform for its own survival. These include generation of metabolic energy (e.g. ATP), generation of reducing agents (e.g. NADH and NADPH), generation of 2,3-bisphosphoglycerate, and maintenance of ionic and concentration gradients across the cell membrane. They lack organelles, such as the nucleus

Correspodence to: Milan Stefek, Institute of Experimental Pharmacology, Slovak Academy of Sciences, Dúbravská cesta 9, 84104 Bratislava, Slovakia

E-mail: exfastfk@savba.sk and mitochondria; energy is generated exclusively by glycolysis (Zancan and Sola-Penna 2005). Since glucose is taken up by erythrocytes in an insulin-independent passive way, the excessive glucose under hyperglycaemic conditions in diabetics is extensively metabolised also by an additional metabolic route, the polyol pathway, leading to the osmolyte sorbitol, produced by aldose reductase (Del Corso et al. 2008; Oates 2008). In diabetic patients, erythrocyte aldose reductase levels were found to correlate well with the severity of diabetic complications, including cataract and retinopathy (Oishi et al. 2002, 2006). The aldose reductase inhibitors fidarestat and epalrestat normalised the elevated sorbitol levels in erythrocytes of diabetic patients (Hamada et al. 2000; Asano et al. 2004). Recently, novel carboxymethylated pyridoindoles, analogues of the efficient 
chain-breaking antioxidant stobadine, were designed, synthesised and characterised as prospective aldose reductase inhibitors endowed with antioxidant activity (Stefek et al. 2008). Of the novel compounds developed (2-benzyl2,3,4,5-tetrahydro-1H-pyrido[4,3-b]indole-8-yl)-acetic acid (compound 1) and (2-phenethyl-2,3,4,5-tetrahydro$1 \mathrm{H}$-pyrido[4,3-b]indole-8-yl)-acetic acid (compound 2) were found to be the most efficient inhibitors of aldose reductase, characterised by the corresponding $\mathrm{IC}_{50}$ values in a micromolar region (Scheme 1).

The aim of this work was to study the effects of the novel pyridoindole derivatives compound 1 and compound 2 on the metabolism of glucose in intact rat erythrocytes under euglycaemic conditions in vitro, including glycolysis and polyol pathway.

\section{Materials and Methods}

\section{Animals and preparation of packed erythrocytes}

Male Wistar rats, 8-9 weeks old, weighing 200-250 g, were used. The animals came from the Breeding Facility of the Institute of Experimental Pharmacology, Dobrá Voda (Slovak Republic). The study was approved by the Ethics Committee of the Institute and performed in accordance with the Principles of Laboratory Animal Care (NIH publication 83-25, revised 1985) and the Slovak law regulating animal experiments (Decree 289, Part 139, July 9th 2003).

The animals in light ether anaesthesia were killed by exsanguinations of the carotid artery. The blood was collected in $3.8 \%$ sodium citrate $(1: 9,1$ vol. of sodium citrate : 9 vol. of blood) and centrifuged at $500 \times g$ for 15 min at $4^{\circ} \mathrm{C}$. Plasma and white blood cells were removed by aspiration. The retrieved erythrocytes were washed three times with 6 vol. of $10 \mathrm{mmol} / \mathrm{l}$ ice-cold isotonic phosphate buffer saline (PBS; $\mathrm{pH} 7.4$ ) containing 1.9 $\mathrm{mmol} / \mathrm{l} \mathrm{NaH}{ }_{2} \mathrm{PO}_{4}, 8.1 \mathrm{mmol} / \mathrm{l} \mathrm{Na}_{2} \mathrm{HPO}_{4}$ and $150 \mathrm{mmol} / \mathrm{l}$ $\mathrm{NaCl}$. The entire procedure was conducted at $0-4^{\circ} \mathrm{C}$. After the last washing, the RBCs were used for further studies. The erythrocyte suspensions used in experiments were prepared daily.

\section{Uptake studies}

Erythrocytes were incubated in the presence of the compounds studied in the final concentration of $100 \mu \mathrm{mol} / 1$ for up to $90 \mathrm{~min}$ in a shaking water bath at $37^{\circ} \mathrm{C}$ (haematocrit 20\%). The incubation mixtures were centrifuged at $700 \times g$ for $10 \mathrm{~min}$ at $4^{\circ} \mathrm{C}$ to pellet the erythrocytes. Then, sodium chloride $(0.1 \mathrm{~g})$ was added to the aliquots of the supernatant $(0.5 \mathrm{ml})$ and after addition of $\mathrm{HCl}$ $(5 \mathrm{~mol} / \mathrm{l}, 0.1 \mathrm{ml}$ ) the mixture was kept on ice for $15 \mathrm{~min}$ for protein precipitation. The mixture was centrifuged at $700 \times g$ for $15 \mathrm{~min}$ at $4^{\circ} \mathrm{C}$. The supernatant $(0.1 \mathrm{ml})$ was diluted with phosphate buffer $\mathrm{pH} 7.4(0.6 \mathrm{mmol} / 1,0.5 \mathrm{ml})$. The fluorescence of the diluted supernatants was measured at excitation/emission wavelengths (275/336 nm), characteristic for the compounds studied (unpublished data), and the concentrations of the compounds 1 and 2 were determined by using appropriate calibration curves. The percentage of a compound uptake into erythrocytes was calculated on the basis of the concentration decrease relative to the initial concentration of the compound in the incubation medium.

\section{Metabolic studies}

The compounds studied were added to the erythrocyte suspensions (haematocrit 20\%) in isotonic PBS to the final concentration of $100 \mu \mathrm{mol} / \mathrm{l}, 30 \mathrm{~min}$ before adding glucose ( $6 \mathrm{mmol} / \mathrm{l}$ final concentration). The incubations were terminated after different time periods by cooling the suspensions in ice bath followed by centrifugation at $700 \times g$ for $15 \mathrm{~min}$ at $4^{\circ} \mathrm{C}$. The supernatant was used for determination of glucose consumption. In separate incubations with $50 \mathrm{mmol} / \mathrm{l} \mathrm{glu}$ cose, lactate production was determined in the supernatant. The pellet of erythrocytes was used for determination of sorbitol concentration.

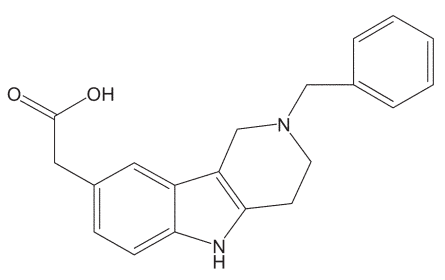

compound 1

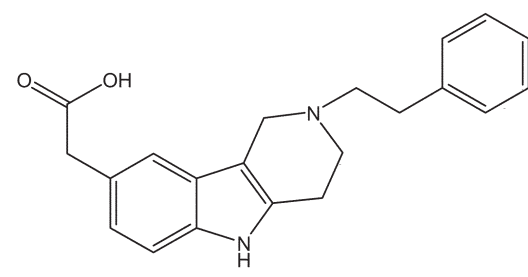

compound 2

Scheme 1. Chemical structure of (2-benzyl-2,3,4,5-tetrahydro-1H-pyrido[4,3-b]indole-8-yl)-acetic acid (compound 1) and (2-phenethyl2,3,4,5-tetrahydro- $1 \mathrm{H}$-pyrido[4,3-b]indole-8-yl)-acetic acid (compound 2). 


\section{Analytical procedures}

Colorimetric kit methods were used for the measurement of the concentrations of glucose (BIO-LA-TEST Glucose GOD 1500 ) and lactate (L-Lactate PAP) in the supernatant.

To determine sorbitol, the pellet of erythrocytes was washed three times with isotonic PBS. Thereafter, ice cold $\mathrm{HClO}_{4}(9 \%, 0.6 \mathrm{ml})$ was added to an aliquot $(0.2 \mathrm{ml})$ of packed erythrocytes to precipitate proteins. The mixture was kept on ice for $30 \mathrm{~min}$ followed by centrifugation at $700 \times g$ for $15 \mathrm{~min}$ at $4^{\circ} \mathrm{C}$. The supernatant was neutralised with $\mathrm{K}_{2} \mathrm{CO}_{3}(4 \mathrm{~mol} / \mathrm{l})$. The neutralised supernatant was used for determination of concentration of sorbitol by modified enzymatic analysis (Mylari et al. 2003). In brief, sorbitol was oxidised to fructose by sorbitol dehydrogenase (SDH) with concomitant reduction of resazurin by diaphorase to the highly fluorescent resorufin. The final concentrations of the assay solutions were: diaphorase (11.5 $\mathrm{U} / 25 \mathrm{ml}$ triethanolamine buffer $), \mathrm{NAD}^{+}(25 \mathrm{mg} / 25 \mathrm{ml}$ triethanolamine buffer), resazurin $(25 \mu \mathrm{l} 2 \mathrm{mmol} / \mathrm{l}$ resazurin solution in $25 \mathrm{ml}$ of triethanolamine buffer), SDH (15.025 $\mathrm{U} / 1 \mathrm{ml}$ triethanolamine buffer). Reaction mixtures were incubated for $60 \mathrm{~min}$ at room temperature with an opaque cover. The sample fluorescence was determined at excitation - $544 \mathrm{~nm}$, emission - $590 \mathrm{~nm}$. After the appropriate blanks were subtracted from each sample, nanomole of sorbitol per millilitre of packed RBCs in each sample was determined by comparison with a linear regression of sorbitol standards.

The osmotic fragility was determined by the degree of haemolysis induced by the changes of osmotic pressure using a step-down protocol with decreasing concentrations of $\mathrm{NaCl}$. The erythrocytes were suspended (haematocrit $0.4 \%$ ) in isotonic PBS containing increasing concentrations of $\mathrm{NaCl}$ from $0-150 \mathrm{mmol} / \mathrm{l}$ and the inhibitor in the final concentration of $100 \mu \mathrm{mol} / \mathrm{l}$. The total haemolysis (100\%) was obtained by incubation of control erythrocytes in $10 \mathrm{mmol} / \mathrm{l}$ hypotonic PBS, pH $7.4(1.9 \mathrm{mmol} / \mathrm{l}$ $\mathrm{NaH}_{2} \mathrm{PO}_{4}, 8.1 \mathrm{mmol} / \mathrm{l} \mathrm{Na} \mathrm{HPO}_{4}$ ). The samples were incubated for $1 \mathrm{~h}$ at $37^{\circ} \mathrm{C}$ in a shaking water bath. After incubation, the erythrocyte suspensions were centrifuged at $700 \times g$ for $15 \mathrm{~min}$ at $4^{\circ} \mathrm{C}$. The haemolysis degree was determined by spectrophotometry of the haemoglobin released into the supernatant, as described by Winterbourn (1990).

\section{Chemicals and instruments}

Compound 1, (2-benzyl-2,3,4,5-tetrahydro-1H-pyrido[4,3b]indole-8-yl)-acetic acid and compound 2, (2-phenethyl2,3,4,5-tetrahydro-1H-pyrido[4,3-b]indole-8-yl)-acetic acid (Scheme 1) were synthesised at the Institute of Experimental Pharmacology, Slovak Academy of Sciences (Stefek et al.
2008) and were available as respective hydrochloride and potassium carboxylate salt. SDH, diaphorase, $\beta-\mathrm{NAD}$, and resazurin were obtained from Sigma-Aldrich Chemie (Steinheim, Germany). BIO-LA-TEST Glucose GOD 1500 kit was from Pliva-Lachema Diagnostika Ltd. (Brno, Czech Republic). L-Lactate (PAP) was from Randox laboratories Ltd. (Antrim, UK). Other chemicals were purchased from local commercial sources and were of analytical grade quality. Spectrophotometric and fluorometric analysis was performed using an Infinite M200 analyser (Tecan, Austria $\mathrm{GmbH})$.

\section{Results}

Figure 1 shows the time course of uptake of compounds 1 and 2 by RBCs in in vitro incubations, as determined by concentration decrease of compounds 1 and 2 in the isotonic buffer medium.

For compound 1, its effect on osmotic fragility of the erythrocyte membrane was assessed. As shown in Figure 2, compound 1 at the concentration $100 \mu \mathrm{mol} / \mathrm{l}$ did not affect significantly the course of osmotic haemolysis of erythrocytes. Analogically, compound 2 at the same concentration had no effect on the RBC fragility (data not shown).

Further, glucose consumption by RBCs incubated with glucose was studied under euglycaemic conditions. Initially, linear decrease in glucose concentration in the incubation medium was observed, reaching approx. 50\% of the starting concentration at the end of a 6-h incubation period (Figure 3). Compounds 1 and 2 did not significantly affect the process.

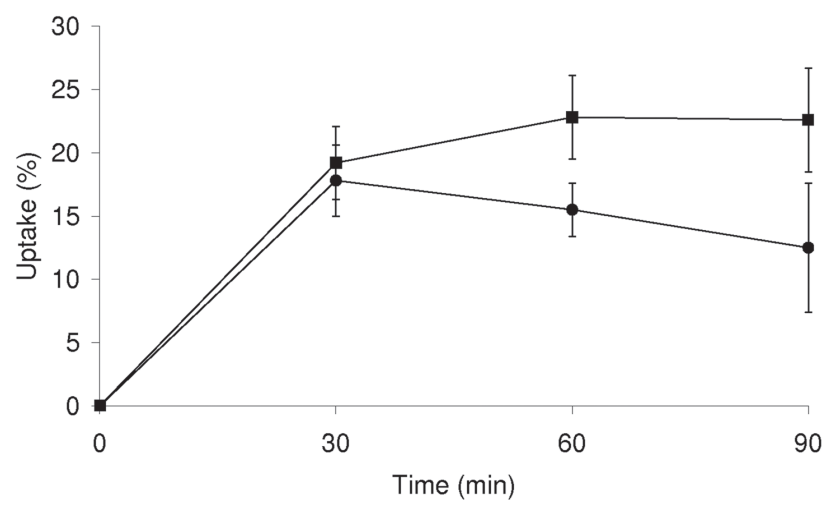

Figure 1. Time course of uptake of compounds 1 and 2 by rat erythrocytes. Compound $1(\bullet)$ and $2(\bullet)$ at $100 \mu \mathrm{mol} / \mathrm{l}$ concentration were incubated for indicated time intervals with isolated washed RBCs (haematocrit $20 \%$ ) at $37^{\circ} \mathrm{C}$. Experimental points represent mean values \pm SD from at least three independent experiments. 


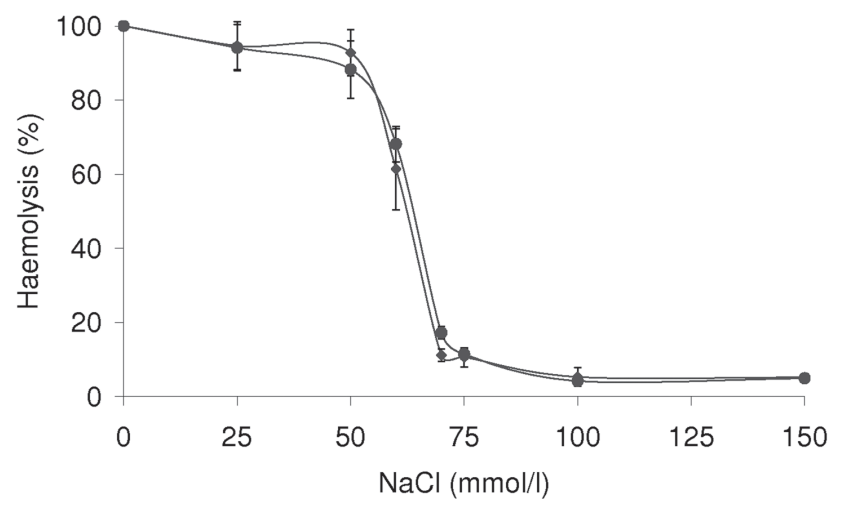

Figure 2. Effect of compound 1 on osmotic fragility of rat erythrocytes. Erythrocyte suspensions ( $0.4 \%$ haematocrit) in $10 \mathrm{mmol} / \mathrm{l}$ phosphate buffer containing increasing concentrations of $\mathrm{NaCl}$ were incubated at $37^{\circ} \mathrm{C}$ for $1 \mathrm{~h}$ in the absence $(\bullet)$ or presence $(\bullet)$ of compound $1(100 \mu \mathrm{mol} / \mathrm{l})$. Experimental points represent mean values \pm SD from at least three independent experiments.

RBC sorbitol levels were determined to assess contribution of the polyol pathway to the apparent glucose clearance in the erythrocyte incubations under both euglycaemic and hyperglycaemic conditions. As shown in Figure 4, no significant accumulation of sorbitol in RBCs was recorded in the incubations with physiological levels of glucose up to $6 \mathrm{~h}$. On the other hand, a significant increase in erythrocyte sorbitol concentration was recorded in the incubations with $50 \mathrm{mmol} / \mathrm{l}$ glucose $(50.2 \pm 1.1 \mathrm{nmol} / \mathrm{ml} \mathrm{RBC} v s .21 .9 \pm$ $3.4 \mathrm{nmol} / \mathrm{ml} \mathrm{RBC}$ for the physiological level in the control erythrocytes) in 3-h incubations.

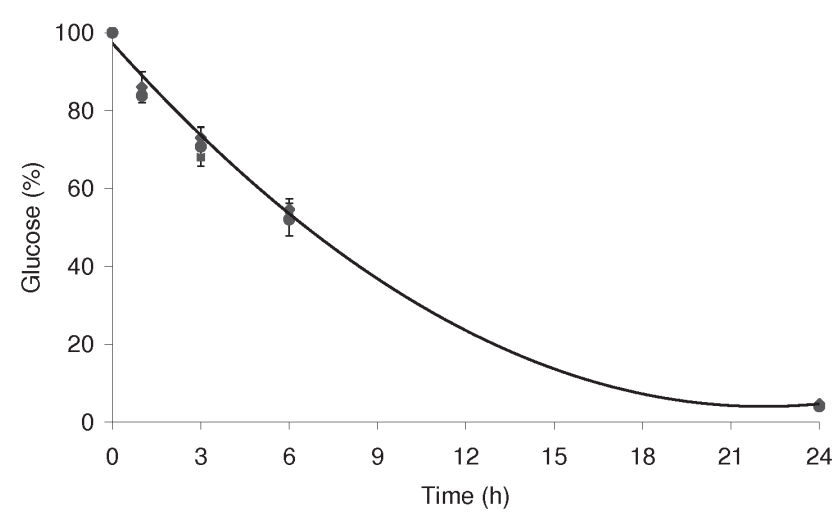

Figure 3. Glucose consumption in rat erythrocytes. Effect of compounds 1 and 2. Erythrocyte suspensions (20\% haematocrit) in 10 $\mathrm{mmol} / \mathrm{l}$ phosphate buffer were incubated with glucose $(6 \mathrm{mmol} / \mathrm{l})$ for indicated time intervals in the absence $(\bullet)$ or presence of compound $1(\bullet)$ and $2(\bullet)$ at $100 \mu \mathrm{mol} / \mathrm{l}$ concentrations at $37^{\circ} \mathrm{C}$. Experimental points represent mean values \pm SD from at least three independent experiments.

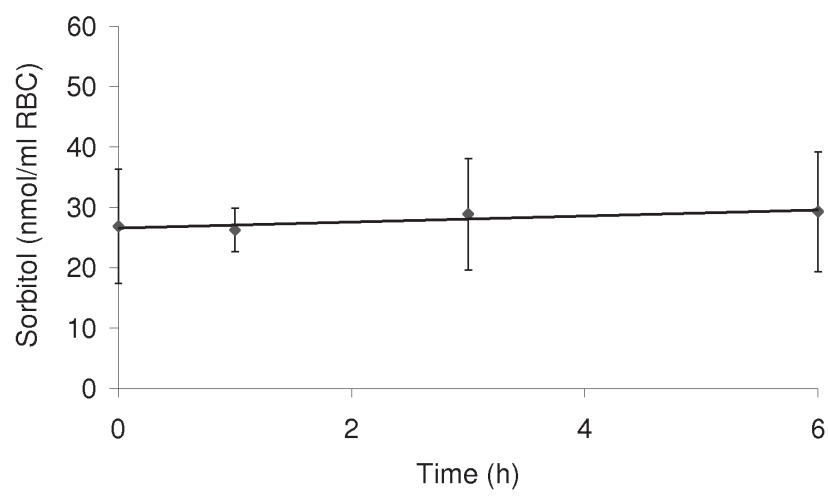

Figure 4. Sorbitol levels in rat erythrocytes. Erythrocyte suspensions (20\% haematocrit) in $10 \mathrm{mmol} / \mathrm{l}$ phosphate buffer were incubated with glucose $(6 \mathrm{mmol} / \mathrm{l})$ for indicated time intervals at $37^{\circ} \mathrm{C}$. Erythrocyte sorbitol level expressed in $\mathrm{nmol} / \mathrm{ml}$ of packed RBCs. Experimental points represent mean values \pm SD from at least three independent experiments.

\section{Discussion}

Recently, novel carboxymethylated congeners of stobadine, an efficient pyridoindole antioxidant (Horakova and Stolc 1998), were designed, synthesised and characterised as uncompetitive inhibitors of aldose reductase, the first enzyme of the polyol pathway, involved in the aetiology of diabetic complications (Stefek et al. 2008). Of them, compounds 1 and 2 were characterised by the corresponding $\mathrm{IC}_{50}$ values in a micromolar region, $18.2 \pm 1.2 \mu \mathrm{mol} / \mathrm{l}$ and $16.7 \pm 1.2$ $\mu \mathrm{mol} / \mathrm{l}$, respectively. The slightly higher inhibitory activity of compound 2 was explained by higher flexibility of the lipophilic phenethyl side chain compared to the benzyl substituent. A reasonable degree of selectivity with respect to the closely related aldehyde reductase was recorded. The inhibitory mode, efficacy and selectivity were preserved even under conditions of prolonged experimental diabetes of rats (Djoubissie et al. 2006). Antioxidant action of the novel compounds was documented in a DPPH test and in liposomal and erythrocyte models oxidatively stressed by peroxyl radicals (Juskova et al. 2008; Stefek et al. 2008). The presence of a basicity centre at the tertiary nitrogen, in addition to the acidic carboxylic function, predisposes these compounds to form double charged zwitterionic species, characterised by the maximal distribution ratio lying near the neutral physiological pH (Stefek et al. 2008). The zwitterionic principle thus may have significant consequences for increased bioavailability of drugs bearing an acidic function. Indeed, by applying criteria of Lipinski's 'rule of five, good oral bioavailability of the novel potential drugs was predicted (Stefek et al. 2008). Presently, the novel compounds are subject to preclinical studies as prospec- 
tive agents with a therapeutic potential in the treatment of diabetic complications.

A critical property for the efficacy of a drug in vivo is its ability to enter target tissues. For the compounds studied, this issue was initially addressed by measuring their ability to penetrate into the intact erythrocytes. As shown in Figure 1, compounds 1 and 2 were readily taken up by the RBCs. The "saturated" value of the uptake at $20 \%$, corresponding to the passive transport through the plasmatic membrane under the experimental conditions used (haematocrit 20\%), was achieved as early as in the $30^{\text {th }} \mathrm{min}$ of incubation. At the concentration studied $(100 \mu \mathrm{mol} / \mathrm{l})$, the compounds studied were not found to affect significantly the osmotic fragility of the erythrocyte plasmatic membrane.

Isolated rat blood cells present a suitable cellular model to study the effects of a drug on the glycolytic pathway. The erythrocytes lack organelles, such as the nucleus and mitochondria; energy is generated exclusively by glycolysis (Zancan and Sola-Penna 2005). Since glucose is taken up by erythrocytes in an insulin-independent passive way, the excessive glucose under hyperglycaemic conditions in diabetics is extensively metabolised also by an additional metabolic route, the polyol pathway, leading to the osmolyte sorbitol, produced by aldose reductase (Del Corso et al. 2008, Oates 2008). As shown in Figure 2, under euglycaemic conditions RBCs extensively consumed glucose leaving less than $5 \%$ of the original concentration after 24 -h incubation. The linear decrease recorded during the initial 6-h period was not significantly affected by the presence of the compounds studied. As shown in separate experiments in the absence of the drugs, erythrocytes incubated with $50 \mathrm{mmol} / \mathrm{l}$ glucose under the same experimental conditions produced $2.89 \pm$ $0.32 \mathrm{mmol} / \mathrm{l}$ lactate during the initial 3 -h period; $3.02 \pm 0.36$ and $3.13 \pm 0.41 \mathrm{mmol} / \mathrm{l}$ were the values of lactate production in the presence of $100 \mu \mathrm{mol} / \mathrm{l}$ of compounds 1 and 2, respectively, showing no significant effect of the compounds on lactate production by metabolising erythrocytes. No significant effect was recorded even in the presence of 250 $\mu \mathrm{mol} / \mathrm{l}$ of compound 1 , giving the value of $2.99 \pm 0.29 \mathrm{mmol} / \mathrm{l}$ of lactate during the initial 3-h incubation period.

As shown in Figure 4, no significant increase in sorbitol level was observed in incubated erythrocytes in the presence of euglycaemic glucose during the initial 6-h period of linear glucose consumption. The recorded values of sorbitol represent the physiological levels of sorbitol embedded in RBCs. These findings are in agreement with the notion that under euglycaemic conditions the polyol pathway does not significantly contribute to metabolic clearance of glucose (Khan et al. 2006). Nevertheless, significant accumulation of sorbitol was recorded in RBCs incubated under hyperglycaemic conditions.

To conclude, the above results show that glycolysis was the sole process responsible for the observed elimination of glucose in the cellular model of intact erythrocytes incubated under euglycaemic conditions. Compounds 1 and 2 were avidly taken up by the cells, yet they did not significantly affect glucose consumption and lactate production nor did they affect osmotic fragility of the erythrocytes. The present experimental findings indicate that compounds 1 and 2 are selective enough not to affect the glycolytic pathway of glucose elimination. The novel carboxymethylated tetrahydropyridoindoles may thus be considered as promising aldose reductase inhibitors, with expected limited side-effects, to be potentially used in prevention and treatment of diabetic complications.

Acknowledgements. This work was supported by VEGA grants No. 2/5005/26, 2/0001/08 and APVV grant No. 51-017905.

\section{References}

Asano T., Saito Y., Kawakami M., Yamada N., Sekino H., Hasegawa S. (2004): Erythrocytic sorbitol contents in diabetic patients correlate with blood aldose reductase protein contents and plasma glucose levels, and are normalized by the potent aldose reductase inhibitor fidarestat (SNK860). J. Diabetes Complicat. 18, 336-342; doi:10.1016/ j.diacomp.2004.04.003

Del Corso A., Cappiello M., Mura U. (2008): From a dull enzyme to something else: facts and perspectives regarding aldose reductase. Curr. Med. Chem. 15, 1452-1461; doi:10.2174/092986708784638870

Djoubissie P.-O., Snirc V., Sotnikova R., Zurova J., Kyselova Z., Skalska S., Gajdosik A., Javorkova V., Vlkovicova J., Vrbjar N., Stefek M. (2006): In vitro inhibition of lens aldose reductase by (2-benzyl-2,3,4,5-tetrahydro$1 \mathrm{H}$-pyrido[4,3-b]indole-8-yl)-acetic acid in enzyme preparations isolated from diabetic rats. Gen. Physiol. Biophys. 25, 415-425

Hamada Y., Nakamura J., Naruse K., Komori T., Kato K., Kasuya Y., Nagai R., Horiuchi S., Hotta N. (2000): Epalrestat, an aldose reductase ihibitor, reduces the levels of $\mathrm{N} \varepsilon$ (carboxymethyl)lysine protein adducts and their precursors in erythrocytes from diabetic patients. Diabetes Care 23, 1539-1544; doi:10.2337/diacare.23.10.1539

Horakova L., Stolc S. (1998): Antioxidant and pharmacodynamic effects of pyridoindole stobadine. Gen. Pharmacol. 30, 627-638; doi:10.1016/S0306-3623(97)00300-5

Juskova M., Snirc V., Gajdosikova A., Gajdosik A., Krizanova L., Stefek M. (2008): Substituted pyridoindoles as aldose reductase inhibitors with antioxidant properties in prevention of diabetic complications: activity studies in rat erythrocytes in vitro. Free Radical Summer School (SFRRE). 30. 8. -5. 9. 2008, Spetses, Greece, p. 61

Khan Z. A., Farhangkhoee H., Chakrabarti S. (2006): Towards newer molecular targets for chronic diabetic complication. Curr. Vasc. Pharmacol. 4, 45-57; doi:10.2174/ 157016106775203081 
Mylari B. L., Armento S. J., Beebe D. A., Conn E. L., Coutcher J. B., Dina M. S., O‘Gorman M. T., Linhares M. C., Martin W. H., Oates P. J., Tess D. A., Withbroe G. J., Zembrowski W. J. (2003): A highly selective, nonhydantoin, non-carboxylic acid inhibitor of aldose reductase with potent oral activity in diabetic rat models: 6-(5-chloro-3-methylbenzofuran- 2-sulfonyl)2-H-pyridazin-3-one. J. Med. Chem. 46, 2283-2286; doi:10.1021/jm034065z

Oates P. J. (2008): Aldose reductase, still a compelling factor for diabetic neuropathy. Curr. Drug. Targets 9, 14-36; doi:10.2174/138945008783431781

Oishi N., Kubo E., Takamura Y., Maekawa K., Tanimoto T., Akagi Y. (2002): Correlation between erythrocyte aldose reductase level and human diabetic retinopathy. Br. J. Ophthalmol. 86, 1363-1366; doi:10.1136/bjo.86.12.1363

Oishi N., Morikubo S., Takamura Y., Kubo E., Tsuzuki S., Tanimoto T., Akagi Y. (2006): Correlation between adult diabetic cataracts and red blood cell aldose reductase levels. In- vest. Ophthalmol. Vis. Sci. 47, 2061-2064; doi:10.1167/ iovs.05-1042

Stefek M., Snirc V., Djoubissie P.-O., Majekova M., Demopoulos V., Rackova L., Bezakova Z., Karasu C., Carbone V., El-Kabbani O. (2008): Carboxymethylated pyridoindole antioxidants as aldose reductase inhibitors: synthesis, activity, partitioning, and molecular modelling. Bioorg. Med. Chem. 16, 4908-4920; doi:10.1016/j.bmc.2008.03.039

Winterbourn C. C. (1990): Oxidative reactions of hemoglobin. Methods Enzymol. 186, 265-272; doi:10.1016/00766879(90)86118-F

Zancan P., Sola-Penna M. (2005): Regulation of human erythrocyte metabolism by insulin: cellular distribution of 6-phosphofructo-1-kinase and its implication for red blood cell function. Mol. Genet. Metab. 86, 401-411; doi:10.1016/j.ymgme.2005.06.011

Received: February 4, 2009

Final version accepted: May 13, 2009 